do serve the types of function we propose for an RPB, albeit for more specific remits. InfraGard, for example, is a US non-profit organization that promotes information exchange and collaboration to protect crucial national infrastructure and key resources. The American National Standards Institute has developed voluntary consensus standards for everything from commercial kitchens to programming languages, and the Smart Grid Interoperability Panel coordinates the development of standards for electricity transmission. These bodies involve stakeholders from both public and private organizations; many started out with public funding and then established funding mechanisms, such as membership support, that allowed them to become largely self-sustaining ${ }^{4}$.

Other countries are already pursuing initiatives that could take on some of the roles we imagine for an RPB. The UK Reproducibility Network, launched last year, consists of universities that have partnered with funders and journals to establish training, infrastructure and networks that help researchers to improve experimental design and to make data available. Japan's Association for the Promotion of Research Integrity (APRIN) has issued a checklist for conducting investigations into research integrity. That was based on a 2017 US effort ${ }^{7}$, itself rooted in work done by the AAAS and various organizations in the United States three decades ago.

In Canada, the Panel on Responsible Conduct of Research, created by its three federal funding agencies, reviews institutional investigations and promotes research integrity. The Australian Research Integrity Committee, an independent body established by the Australian Research Council and the National Health and Medical Research Council, serves similar functions.
Last June, the UK Parliament issued a report that recommended establishing a national oversight committee to champion research integrity and increase transparency. Similar efforts are in place in countries including Austria, Denmark, Finland, France and Germany. If the United States does not follow suit, it could see its international scientific leadership start to fade.

We propose that the US board will not perform misconduct investigations or oversee those done by universities or other organ-

\section{"There are many perverse incentives in science."} izations. The role of the US board is to work with institutions to reduce the incidence of misconduct and other practices that damage the credibility of science. An RPB should support the specific work of journals, funders, institutional leaders and individual scientists striving for the same. It should also find ways to implement cost-effective, streamlined research processes, fairer and more-effective workforce development, and ways to eliminate sexual and gender harassment.

As a first step, the US National Academy of Sciences is convening a plenary session on the trustworthiness of science at its annual meeting in April. This will be the first opportunity for leaders of the US scientific enterprise to discuss the role of a national board for research integrity. As a follow-up, we propose a two-day meeting of stakeholders in late 2019 to determine what sort of formal entity is needed, what it should do, what kind of support it would need, and under what authorization it would operate. Invitees would include journal editors, university leaders, the US National Science Foundation and the US National Institutes of Health.
There are many perverse incentives in science, and few organized forces to counter them. A research policy board, first recommended more than 25 years ago, will benefit both science and scientists. We must act to create it now.

C. K. Gunsalus is director of the National Center for Professional and Research Ethics at the University of Illinois, UrbanaChampaign, USA. Marcia K. McNutt is president of the US National Academy of Sciences. Brian C. Martinson studies research integrity and behavioural change at the HealthPartners Institute in Bloomington, Minnesota, USA. Larry R. Faulkner is president emeritus of the University of Texas at Austin, USA. Robert M. Nerem is institute professor emeritus at the Georgia Institute of Technology, Atlanta, USA. e-mails:gunsalus@illinois.edu; mmcnutt@nas.edu

\footnotetext{
1. National Academy of Sciences, National Academy of Engineering, and Institute of Medicine. Responsible Science, Volume I: Ensuring the Integrity of the Research Process (National Academies Press, 1992)

2. National Academies of Sciences, Engineering, and Medicine. Optimizing the Nation's Investment in Academic Research (National Academies Press, 2016)

3. National Academies of Sciences, Engineering, and Medicine. Fostering Integrity in Research (National Academies Press, 2017).

4. National Academies of Sciences, Engineering, and Medicine. The Next Generation of Biomedical and Behavioral Sciences Researchers: Breaking Through (National Academies Press, 2018).

5. Michalek, A. M., Hutson, A. D., Wicher, C. P. \& Trump, D. L. PLOS Med. 7, e1000318 (2010)

6. McNutt, M. K. et al. Proc. Natl Acad. Sci. USA 115 2557-2560 (2018).

7. Gunsalus, C. K. Marcus, A. R. \& Oransky, I. J. Am. Med. Assoc. 319, 1315-1316 (2018).
}

B.C.M. declares competing financial interests; see go.nature.com/2sgqyy 5 for details.

\title{
Three secrets of survival in science advice
}

\section{Be impartial, humble and good value, urge Chris Tyler and Karen Akerlof.}

$\mathrm{T}$ he offices that give science advice to politicians are among the most important public bodies you've never heard of. Some nations - notably the United States and Denmark - have closed or stopped funding them. Elsewhere, these bodies are thriving: in the United Kingdom and France, for example. Differences between the healthy and the defunct hold lessons for countries that hope to improve the use of science in law-making and political debate.

Spain's national parliament, for instance, plans to open a science and technology advisory unit this summer. In the United States, hopes have been raised this past year of the return of something like the much-missed Office of Technology Assessment (OTA), shuttered in the mid-1990s. This spring, Congress is likely to consider funding for science and technology advice in its budget appropriations for the legislative branch.
Here we offer a three-step survival guide for legislative science and technology advisory bodies (LSTABs). Our recommendations are based on the key functions and factors that seem to have led to the long-term success or failure of such bodies.

\section{IN-HOUSE EXPERTISE}

Roughly $90 \%$ of legislatures lack the kind of scientific and technical advisory system that they need to be effective. Sadly, some 
> legislatures that had such a system have lost it: the United States (in 1995), Italy (in 2009) and Denmark (in 2011).

Most northern European democracies have LSTABs. These have been around since the 1980s, inspired by the defunct OTA. One of us (C.T.) is the former director of the United Kingdom's version, the Parliamentary Office of Science and Technology (POST). France has the Parliamentary Office for the Evaluation of Scientific and Technological Options (OPECST). The Netherlands, Norway, Germany, Austria, Switzerland and others also have similar systems.

These bodies offer legislators independent, politically impartial, expert scientific and technical advice on myriad topics. Legislating is tough: values, economics, law, social norms and politics frequently collide, leaving only difficult choices. Democracy does not work properly if politicians struggle to get their facts straight. That is where LSTABs come in.

They tend to operate behind the scenes with little fanfare, and are small compared with their executive counterparts - often having one-tenth or one-hundredth of the staff. And they aim obsessively for political and scientific impartiality. They work proactively on a dizzying array of subjects. At any one time, there are dozens of ongoing inquiries that might take weeks or months to complete. Current topics across various LSTABs include delivery drones (Austria), the digital society (the Netherlands), human genome editing (Germany), batterycharging infrastructure for electric vehicles (France) and robotics (United Kingdom).

Most legislatures also have some kind of on-demand research service that responds to legislators' immediate requests for information. Examples include the US Congressional Research Service and the two UK Parliament 'library' research services in the House of Commons and the House of Lords. Often these are swamped with work, answering questions and providing background briefings in real time. The kind of in-depth, long-range advice offered by LSTABs is beyond the capacity of many of these services.

LSTABs tell politicians the things they need to know but didn't think to ask. The most important skills of staff are distillation and impartiality — scientific and technical information is often hard to understand, and its political context can be extremely complicated. They summarize complex information into easy-to-understand nuggets, and put them in the context of a wide range of policy options that are relevant to the work of every politician, no matter to which party they belong.

But LSTABs can be politically vulnerable. The factors that led to the demise of the US OTA have been well documented (see, for example, refs 1-3). Perceived politicization, a lack of cross-party support and budget cuts took their toll. Italy's advisory body was dissolved when its chairman, Sandro De Franciscis, left parliament. Denmark's LSTAB had its funding removed in an apparent budgetary oversight.

This is why it is worth analysing success stories.

\section{SUCCESS STORIES}

That brings us to the LSTABs of the United Kingdom and France. Like the OTA (and Spain's planned advisory unit), both bodies are part of the internal parliamentary bureaucracy. Unlike the OTA, they are thriving. The United Kingdom's POST, established in 1989, comprises about a dozen advisers. It does a wide range of work, from organizing seminars for parliamentarians to writing 'POSTnotes' - summaries on topics as diverse as quantum computing and inequality.

France's OPECST is different. Established in 1983, it is a committee of politicians tasked with helping parliament to

\section{SURVEY}

\section{Gaps in science advice}

From September to November last year, we asked academics, science advisers and policymakers to identify the most pressing research questions that, if answered, could broaden our theoretical and empirical understanding of the provision of science advice for legislatures. Our study was funded by the US National Science Foundation.

The 183 respondents were from 53 countries and came up with 254 questions. These included how existing science advisory systems work, and how to design systems for information creation, communication and use in the many countries that don't have them.

According to these experts, fundamental information about legislative science advice remains unknown (see also refs 5, 6). Gaps include what types of scientific information are used in legislatures; how different institutional approaches to legislative science advice influence its nature, quality and relevance; and how the requirements and needs of a science advice system differ across countries.

The field needs broader partnerships between academics and practitioners to plug these knowledge gaps. C.T. \& K.A. make "enlightened decisions" by advising it on the consequences of choosing various scientific and technological options. The committee has the same standing as other parliamentary committees. So, in addition to producing technology assessments and reports, it scrutinizes the executive body and makes legislative recommendations.

These LSTABs have weathered times of trial. For example, there was an attempt in 2012 to cut POST's funding. The fact that this didn't work illustrates the robustness of the institution.

It is clear that certain factors have led to long-term stability for POST and OPECST. Which of these might be carried across to a resurrected OTA in the United States, or a Spanish equivalent? We have three recommendations.

Make bipartisanship real. Political oversight of the OTA was intended to be bipartisan. It was governed by a board of politicians from both parties and both houses. Yet it was perceived as partisan from the outset, largely because of the role of Senator Edward Kennedy (Democrat) in its establishment. He was twice its chairman, and had a consistent influence ${ }^{4}$. Making bipartisanship real in both practice and perception is a key feature of both the French and UK offices.

The French have designed a process that gives their bipartisanship teeth. Each OPECST study is overseen and communicated back to parliament by two rapporteurs, who are a representative mix of the following: each political wing (majority and opposition parties), each chamber (a senator and a deputy) and each gender; OPECST calls it 'triple parity' matching. These rapporteurs have constitutional powers, for example, to investigate any state agency, and their findings are designed to be used in legislative work and budget discussions.

This approach ensures that proposals OPECST makes have cross-party support from the start. For example, an OPECST report on bioethics in October 2018 was overseen by Jean-François Eliaou from the centrist party La République En Marche! in the lower chamber, and by Annie Delmont-Koropoulis from the centre-right Les Républicains in the upper chamber. Despite existing in such a highly political environment, this structure makes it much easier to maintain political support for the office itself.

In the United Kingdom, bipartisanship is encouraged through the composition of the POST Board. It features politicians from all the main parties and representatives from both chambers, and there are parliamentary civil servants and scientists from national research academies. The UK Parliament as a whole has a tradition of 'leaving party politics at the committee-room door'. This is 
